\title{
Cost of medical student virtual conference registration in ophthalmology and urology during the COVID-19 pandemic
}

https://doi.org/10.1515/jom-2021-0258

Received November 3, 2021; accepted January 12, 2022;

published online January 28, 2022

To the Editor:

We read with interest "Analyzing the Cost of Medical Student Virtual Conference Registration by Specialty During the COVID-19 Pandemic" [1] by Veyg and Gurevich, and commend them for their research analyzing the cost of medical student virtual conference registration by specialty during the COVID-19 pandemic. In their study, they found that "research intensive" specialties tend to have higher conference attendance fees, which may result in repulsing students with a lack of resources or funds from attending those conferences and establishing crucial networks with doctors within their respective fields [1].

In an effort add to their research, we compared the costs of virtual conferences to research output by students matching into ophthalmology and urology. Because the SF Match does not make this information readily available, we found studies and surveys published within the last 5 years. While recent studies do not analyze all research accomplishments, such as presentations, Bargoud et al. reported that the average publication number of all successfully matched ophthalmology residents was $1.23 \pm 0.01$ in 2018 [2]. The number of publications has increased in recent years. Srinivasan et al. found the average number of publications of successfully matched residents was $2.95 \pm 0.33$ for the class of 2022 in their

*Corresponding author: Justin T. Bradshaw, OMS II, Rocky Vista University College of Osteopathic Medicine Southern Utah Campus, 255 E. Center Street, Ivins, UT 84738, USA,

E-mail: justin.bradshaw@rvu.edu

Lawsen M. Parker, OMS II, Westin J. Wong, OMS II and Steven P. Gawrys, OMS II, Rocky Vista University College of Osteopathic Medicine Southern Utah Campus, Ivins, UT, USA recent analysis of the top 30 ophthalmology residency programs in the United States [3]. Additionally, a 2018 study found that $99 \%$ of all ophthalmology applicants had at least one publication [4]. Urology had a similar average number of publications among successfully matched residents in the top 50 residency programs at $2.38 \pm 4.19$ in 2020 [5]. Urology also demonstrates higher interview rates among applicants with more research experiences [6].

Although the SF Match does not publicize average research accomplishments of candidates, it can be determined that ophthalmology and urology are "research intensive" specialties based on average publications among applicants in recent research. The conference fee for student members of the American Academy of Ophthalmology (AAO) is $\$ 75$ (Figure 1) and there is no option for non-member student attendance [7]. Fees for the annual urology conference are $\$ 50$ and $\$ 100$ for American Urological Association (AUA) student members and non-member students, respectively (Figure 1) [8]. These findings only include basic virtual conference fees without upgrades.

Although research intensive specialties were found to have higher fees for conference attendance, ophthalmology and urology conferences have fees that more similarly resemble fees for members of non-researchintensive specialties. Despite having lower conference registration fees than other "research intensive" specialties, we agree that free conference registration would help reduce the financial burden on already indebted medical students. Lastly, we invite the SF match to publish transparent metrics that differentiate the research experiences of recently matched residents.

Research funding: None reported.

Author contributions: All authors provided substantial contributions to conception and design, acquisition of data, or analysis and interpretation of data; all authors drafted the article or revised it critically for important 


\section{Conference Fees by Specialty for Student}

$\$ 140.00$

Members

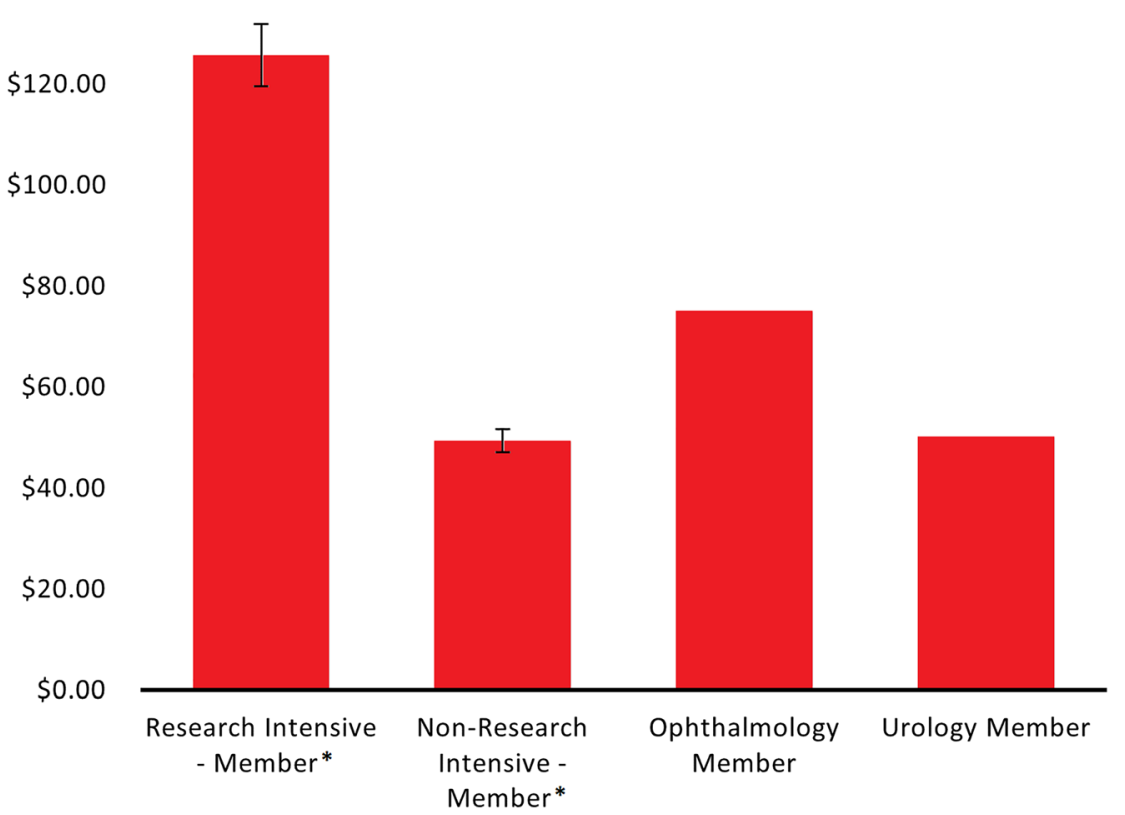

Figure 1: Ophthalmology and urology national conference attendance fees for student members compared to the average national conference attendance fees, discovered by Veyg and Gurevich [1], for student members of "research intensive" and "non-research intensive" specialties during the COVID-19 pandemic. * Data collected by Veyg and Gurevich [1]. intellectual content; all authors gave final approval of the version of the article to be published; and all authors agree to be accountable for all aspects of the work in ensuring that questions related to the accuracy or integrity of any part of the work are appropriately investigated and resolved.

Competing interests: None reported.

\section{References}

1. Veyg D, Gurevich R. Analyzing the cost of medical student virtual conference registration by specialty during the COVID-19 pandemic. J Osteopath Med 2021;121:843-8.

2. Bargoud AR, Thangamathesvaran L, Patel VR, Henseler R, Kass W, Khouri AS. Quantifying the impact of research on matching into ophthalmology residency. J Acad Ophthalmol 2018;10:e133-9.
3. Srinivasan N, Zhou B, Taruvai V, Nadkarni S, Song A, Khouri AS. Catching eyes: an analysis of medical student publications in the ophthalmology match. Invest Ophthalmol Vis Sci 2021;62:2660.

4. Siatkowski RM, Mian SI, Culican SM, Green LK, Sun G, Waxman EL, et al. Probability of success in the ophthalmology residency match: three-year outcomes analysis of San Francisco matching program data. J Acad Ophthalmol 2018;10:e150-7.

5. Warren CJ, Wisener J, Chang C, Abdelmalek G, Gad B, Nadkarni S, et al. PubMed-indexed research productivity of students matching at top urology programs: 2017-2020. Urology 2020;144:52-8.

6. Heard JR, Werle L, Kasarla N, Winer AG. Catching a big fish with a small net: factors associated with first-choice match from urology residency applicants' self-reported data. Urol Pract 2021;8:374-9.

7. American Academy of Ophthalmology. Registration information. AAO Website. Available from: https://www.aao.org/annual-meeting/ registration/registration-information [Accessed 3 Nov 2021].

8. American Urological Association. AUA2021 registration options. AUA 2021. Available from: https://www.aua2021.org/register/ aua2021-registration-options [Accessed 3 Nov 2021]. 